\title{
PROFIL USAHA DAN STRATEGI BISNIS KERAJINAN MENDONG KELURAHAN SINGKUP KECAMATAN PURBARATU KOTA TASIKMALAYA
}

\author{
BUSINESS PROFILE AND BUSINESS STRATEGY OF MENDONG CRAFT \\ KELURAHAN SINGKUP KECAMATAN PURBARATU KOTA TASIKMALAYA \\ YUDHA ARDIANSYAH*, YUSNITA PRIMAWATI, ZULFIKAR NOORMANSYAH \\ Program Studi Agribisnis Pasca Sarjana Universitas Siliwangi \\ *Email : yudaardi6@gmail.com
}

\begin{abstract}
ABSTRAK
Penelitian ini bertujuan untuk mengetahui profil usaha, serta strategi yang dapat diterapkan untuk mengembangkan bisnis kerajinan mendong. Data dikumpulkan dengan metode wawancara dan dokumentasi, dianalisis dengan teknik kualitatif dan SWOT. Hasil penelitian menunjukkan bahwa profil usaha dapat ditinjau dari aspek produksi, aspek sumber daya manusia, aspek pemasaran, dan aspek keuangan. Aspek produksi meliputi alat produksi yang berupa ATBM, dengan bahan baku utama mendong lembaran yang telah ditenun dengan berbagai pewarna tekstil untuk dijadikan kerajian tangan berbagai fungsi. Aspek sumber daya manusia adalah tenaga kerja yang dibutuhkan untuk membuat kerajinan mendong dalam satu perusahaan kurang lebih 20 orang. Sistem pembayaran pengrajin disesuaikan dengan bidang yang dikerjakan dan tenaga kerja pengerajin secara umum merupakan buruh borongan. Aspek pemasaran kerajinan mendong masih terkendala dalam promosi. Aspek keuangan dari usaha kerajinan mendong masih perlu ditingkatkan dalam pembukuan yang tersusun lengkap. Dari analisis SWOT dapat diketahui bahwa produk yang dihasilkan adalah produk kerajinan yang memiliki kualitas yang bagus sehingga dapat dijadikan kekuatan untuk menangkap peluang pasar dengan jumlah pesaing yang cukup tinggi. Dukungan pemerintah sangat dibutuhkan terutama dalam memberikan fasilitasi dan mengikutsertakan dalam berbagai pameran kerajinan. Strategi Bisnis usaha kerajinan mendong diutamakan adalah pengembangan dalam inovasi produk agar lebih kreatif dalam penciptaan bentuk kerajinan tangan yang unik dan berciri khas.
\end{abstract}

Kata kunci: profil usaha, strategi bisnis, analisis SWOT

\begin{abstract}
This study aims to determine the business profile and strategies that can be applied to develop a mendong craft business. Data were collected by interview and documentation methods, analyzed using qualitative techniques and SWOT. The results showed that the business profile can be viewed from the aspects of production, aspects of human resources, aspects of marketing, and aspects of finance. The production aspect includes production equipment in the form of ATBM, with the main raw material of mendong sheets that have been woven with various textile dyes to be used as handicrafts for various functions. The human resource aspect is the labor required to make mendong crafts in a company of approximately 20 people. The craftsmen's payment system is adjusted to the field they are working on and the craftsmen workforce in general is piece work. The marketing aspect of Mendong handicrafts is still constrained by promotion. The financial aspect of the mendong handicraft business still needs to be improved in complete compiled bookkeeping. From the SWOT analysis, it can be seen that the product produced is a handicraft product that has good quality so that it can be used as a strength to seize market opportunities with a high enough number of competitors. Government support is needed, especially in providing facilitation and participating in various craft fairs. The business strategy of mendong handicraft business is the development of product innovation to be more creative in creating unique and distinctive handicraft forms.
\end{abstract}

Keywords: business profile, business strategy,SWOT analyze 
PENDAHULUAN

Industri kreatif di Indonesia memiliki potensi yang sangat baik di setiap daerahnya. Termasuk di provinsi Jawa Barat yang di kenal sebagai pusatnya kreativitas dan pusat kebudayaan Sunda sehingga secara historis telah banyak melakukan kegiatan ekonomi yang termasuk dalam industri kreatif. Salah satu daerah yang berkembang dalam hal industri kreatif di provinsi Jawa Barat yaitu Kota Tasikmalaya. Dimana, Kota Tasikmalaya memiliki beberapa komoditi industri kreatif yaitu beberapa kerajinan tangan seperti kerajinan Mendong, kerajinan bambu, bordir, payung geulis, kelom geulis, kerajinan kayu, batik dan makanan tradisional khas Tasikmalaya. Kerajinan Mendong adalah salah satu komoditi kreatif Kota Tasikmalaya yang berkontribusi sebesar $8 \%$ dalam penyerapan tenaga kerja walaupun masih lebih rendah dari industri bordir tetapi lebih baik dalam penyerapan tenaga kerja, nilai investasi dan nilai produksi jika dibandingkan dengan industri batik. (Diskumkmperindag,2019)

Kementerian Perdagangan Indonesia menyatakan bahwa Industri kreatif adalah industri yang berasal dari pemanfaatan kreativitas, keterampilan serta bakat individu untuk menciptakan kesejahteraan serta lapangan pekerjaan dengan menghasilkan dan mengeksploitasi daya kreasi dan daya cipta individu tersebut. Menurut Kementrian Negara Koperasi dan Usaha Kecil dan Menengah Republik Indonesia (2009) salah satu bentuk agroindustri di Indonesia adalah agroindustri kerajinan yang saat ini cukup berkembang di masing-masing daerah. Dengan ciri-ciri usaha yang bertumpu pada usaha rumah tangga (mikro) atau industri , kecil dan menengah (UMKM).

Kerajinan Mendong merupakan kreasi anyaman dan distribusi produk kerajinan yang terbuat dari mendong dengan dikreasikan menggunakan desain produk yang dibuat dan menggunakan desain fashion untuk meningkatkan produktivitas dan kreativitasnya. Bentuk kerajinan mendong adalah kerajinan anyaman yang menggunakan bahan baku tanaman mendong yang dikreasikan menjadi sebuah anyaman yang lebih bernilai tinggi. Kerajinan anyaman mendong merupakan kerajinan masyarakat Kelurahan Singkup Kecamatan Purbaratu Kota Tasikmalaya.

Kerajinan Mendong di Kecamatan Purbaratu Kota Tasikmalaya yang merupakan sentra industri kerajinan mendong Tahun 2016 masih ada 34 usaha kerajinan Mendong dan pada tahun 2017 
sampai 2019 hanya ada 26 usaha kerajinan Mendong(Diskumkmperindag,2019).

Menurunya usaha kerajinan mendong di Kecamatan Purbaratu tidak berlaku untuk UMKM kerajinan mendong yang masih berproduksi sampai sekarang, dimana produknya mulai berkembang dengan inovasi bentuk produk yang bervariasi.

Suryana (2008) menyatakan bahwa profil usaha dalam penyusunan studi kelayakan usaha yaitu gambaran umum perusahaan, perizinan, aspek teknis produksi/operasi, aspek pemasaran, aspek manajemen, serta aspek keuangan. Menurut Griffin pada tahun 2004 menyatakan bahwa gambaran usaha dilihat dari bidang organisasi manajemen yang terdiri dari bidang pemasaran, bidang keuangan, bidang operasional, bidang sumber daya manusia, dan bidang administrasi.

Strategi bisnis adalah kemampuan pengusaha/perusahaan dalam analisis lingkungan eksternal dan internal perusahaan, perumusan (formulasi) strategi, pelaksanaan (implementasi) rencana-rencana yang dirancang untuk mencapai sasaran-sasaran perusahaan, serta melakukan evaluasi untuk mendapatkan umpan balik dalam merumuskan strategi yang akan datang. Variabel ini diukur dengan 3 dimensi yaitu : differentiation, low cost, dan focus strategy. (Mahmud dan Anomsari, 2011:3)

Tujuan dari penelitian ini yaitu untuk memberikan gambaran usaha (profil usaha) kerajinan mendong dari aspek produksi, sumber daya manusia, pemasaran dan keuangan serta untuk menyususun strategi bisnis yang dapat diterapkan pada usaha kerajinan mendong di Kelurahan Singkup Kecamatan Purbaratu.

\section{METODE PENELITIAN}

Penelitian ini dilakukan pada bulan Desember 2020 yang berlokasi di Kelurahan Singkup Kecamatan Purbaratu Kota

Tasikmalaya. Penelitian ini merupakan penelitian deskriptif, Subjek penelitian ini adalah Usaha Kerajinan Mendong, sedangkan yang menjadi objek penelitian adalah Profil Usaha Kerajinan Mendong.

Jenis data yang dipergunakan adalah data kualitatif berupa hasil wawancara dengan pengusaha kerajinan mendong, pengrajin mendong, petani mendong, dan pengepul mendong. Data kuantitatif berupa data keuangan yang dimiliki pengusaha kerajinan mendong. Sumber data yang digunakan dalam penelitian ini adalah data primer berupa 
hasil wawancara serta data skunder berupa hasil dokumentasi yang telah dimiliki oleh pengusaha kerajinan mendong. Adapun teknik analisis yang dilakukan dalam penelitian ini yaitu analisis deskriptif dengan pendekatan kualitatif untuk menggambarkan profil usaha kerajinan mendong, yang kemudian dilanjutkan dengan analisis SWOT untuk memperoleh strategi bisnis yang tepat digunakan pengusaha kerajinan mendong di Kelurahan Singkup dalam mengembangkan usahanya.

\section{HASIL DAN PEMBAHASAN}

Profil Usaha Kerajinan Mendong di Kelurahan Singkup Ditinjau Dari Aspek Produksi

Dari hasil wawancara dapat diperoleh data tentang profil usaha ditinjau dari aspek produksi yaitu (a) lokasi para pengerajin mendong di Kelurahan Singkup secara keseluruhan memiliki tempat khusus untuk berproduksi. Produksi dilakukan di rumah pribadi pemilik dalam membuat kerajinan dan di rumah pribadi pengrajin dalam membuat tenun mendong, (b) kerajinan mendong dihasilkan dari bahan baku mendong kering yang sudah diproses dengan pewarnaan tekstil dan penjemuran kemudian ditenun sehingga berbentuk lembaran, (c) alat yang dipakai dalam proses produksi anyaman mendong menggunakan alat tenun ATBM (alat tenun bukan mesin) injak. Untuk proses pembuatan kerajinan mendong (handycraft) alat yang digunakan adalah karton untuk membuat pola, gunting, cutter, lem, tali dan bahan lain yang sudah dibentuk sesuai keinginan konsumen, (d) sarana, dalam melaksanakan produksi sarana yang dimaksudkan adalah jalan raya, listrik, dan air, (e) kapasitas produksi setiap lembar anyaman mendong ukuran 10 meter dapat dilakukan proses penganyaman dengan ATBM selama 5 jam sehingga pengerajin anyaman mendong dapat menentukan target produksi setiap bulannya yaitu rata-rata 50-60 lembar anyaman mendong per-satu ATBM. Sedangkan untuk pembuatan kerajinan mendong dilakukan sesuai jumlah pesanan konsumen.

\section{Profil Usaha Kerajinan Mendong di Kelurahan Singkup Ditinjau Dari Aspek Sumber Daya Manusia}

Hasil penelitian profil usaha kerajinan mendong ditinjau dari aspek sumber daya manuasia adalah sebagai berikut (a) sistem perencanaan kerja dilaksanakan secara sederhana menyesuaikan dengan kebutuhan. Jumlah tenaga kerja yang dibutuhkan untuk 
membuat kerajinan mendong dalam satu perusahaan kurang lebih 20 orang. Sistem pembayaran pengrajin disesuaikan dengan bidang yang dikerjakan dan tenaga kerja pengerajin secara umum merupakan buruh borongan dengan upah Rp.7.000,- sampai Rp. 30.000,-/jumlah produk yang dibuat, (b) pengembangan tenaga kerja (buruh) dilakukan secara sederhana oleh para pengusaha kerajinan mendong. Pengusaha mendapatkan pengetahuan kreasi kerajinan melalui pelatihan dan pengalaman pribadi kemudian ilmu tersebut dikembangkan kepada pekerja untuk menciptakan kreasi kerajinan mendong. Berdasarkan hasil wawancara, pengrajin mendong di Kelurahan Singkup pernah mengikuti pelatihan dan pembinaan yang dilakukan dari Dinas Koperasi, UMKM, Perindustrian dan

Perdaganagan Kota Tasikmalaya, (c) penilaian prestasi bersumber dari waktu dan hasil pekerjaan yang dihasilkan oleh para pengrajin, (d) sistem pemberian kompensasi dilakukan menggunakan sistem borongan, yakni pembayaran upah kerja tergantung banyaknya hasil yang dikerjakan dan waktu penyelesaian. Sedangkan untuk pemeliharaan iklim kerja para pengusaha memiliki ruang produksi yang luas sehingga para pengrajin dapat menyelesaikan pekerjaannya dengan

konsentrasi $\begin{aligned} & \text { penuh dan sesuai } \\ & \text { dengan target yang } \\ & \text { pengusaha. }\end{aligned}$
diharapkan

\section{Profil Usaha Kerajinan Mendong di Kelurahan Singkup Ditinjau Dari Aspek Pemasaran}

Profil usaha kerajinan mendong ditinjau dari aspek pemasaran adalah sebagai berikut : (a) pembuatan produk kerajinan mendong disesuaikan dengan permintaan pasar, yakni para pengusaha membuat produk yang biasanya laku dipasaran serta produk yang dipesan langsung oleh konsumen. Produk utama para pengusaha kerajinan mendong adalah produk perlengkapan rumah tangga, produk asesoris, furniture dan yang paling banyak adalah kotak (box) serbaguna, (b) para pengerajin anyaman mendong menjual hasil anyaman kepada pengepul dengan harga Rp.3.000,- sampai Rp.3.500/meter kemudian pengusaha

membeli lembaran anyaman mendong dari pengepul dengan harga Rp. 10.000,/meter. Tenun mendong oleh pengusaha kerajinan dibuat produk handycraft berbagai bentuk dengan kisaran harga Rp10.000 - Rp. 500.000. Daerah pemasaran kerajinan mendong selain di Tasikmalaya adalah Jakarta, Malang dan Yogyakarta yang selanjutnya sebagian 
produk diekspor ke Amerika, (c) sarana promosi yang pernah diikuti oleh pengusaha kerajinan mendong di Kelurahan Singkup yaitu pameran difasilitasi oleh Dinas Koperasi ,UMKM, Perindustrian dan Perdagangan Kota Tasikmalaya dan Kamar Dagang dan Industri (KADIN). Berdasarkan hasil wawancara dan dokumentasi salah satu pengusaha kerajinan mendong di Kelurahan Singkup juga pernah mengikuti pameran di Vietnam dan Singapura.

\section{Profil Usaha Kerajinan Mendong di Kelurahan Singkup Ditinjau Dari Aspek Keuangan}

Untuk produksi kerajinan mendong yang paling dominan yaitu box serbaguna berbagai ukuran dan model. Sumber dana utama berasal dari modal sendiri dengan modal awal usaha sebesar Rp. 1.500.000,pada Tahun 1996. Selain modal sendiri para pengrajin mendong di Kelurahan Singkup mendapat bantuan pemerintah baik pusat maupun daerah untuk ATBM. Untuk pengembangan usaha pengusaha kerajinan mendong di Kelurahan Singkup mendapatkan Kredit Usaha Rakyat dari Bank Negara Indonesia (BNI) dengan pinjamann dana sebesar Rp.200.000.000,(dua ratus juta rupiah) pada tahun 2010 dengan bunga $10 \%$ per tahun. Untuk pembukuan (proyeksi neraca, proyeksi laba rugi, dan proyeksi arus kas) para pengusaha kerajinan mendong di Kelurahan Singkup sama sekali tidak memiliki pembukuan secara khusus. Dari hasil wawancara mereka hanya mencatat pengeluaran dan pemasukan dari setiap transaksi secara sederhana.

\section{STRATEGI BISNIS}

Berdasarkan hasil wawancara mengenai profil usaha kerajinan mendong di Kelurahan Singkup dapat dirumuskan kekuatan, kelemahan, peluang, serta ancaman di setiap aspek sebagai berikut :

(1) aspek produksi, kekuatan yang dimiliki oleh usaha kerajinan mendong ditinjau dari aspek produksi yaitu produk kerajinan mendong yang dihasilkan oleh para pengerajin mendong di Kelurahan Singkup merupakan hasil kerajinan yang unik dengan kualitas yang bagus. Kelemahan yang dimiliki oleh usaha kerajinan mendong ditinjau dari aspek produksi yaitu perencanaan sistem produksi yang belum maksimal, yakni perencanan hanya hanya ditentukan dari besar kebutuhan. Peluang yang dimiliki oleh usaha kerajinan mendong

ditinjau dari aspek produksi yaitu para pengerajin mendong telah menjalin kerja sama terhadap para pemasok bahan baku sehinga dapat memperoleh harga yang 
lebih rendah, serta ancaman yang dimiliki oleh usaha kerajinan mendong ditinjau dari aspek produksi yaitu terdapat kenaikan harga bahan baku terutama bahan baku mendong kering yang di datangkan dari luar Kota Tasikmalaya. (2) Aspek sumber daya manusia, kekuatan dari aspek sumber daya manusia yang dimiliki oleh usaha kerajinan mendong yaitu para buruh yang bekerja sebagaian besar adalah anggota keluarga atau kerabat sehingga mempermudah koordinasi, serta pemilik telah mengikuti berbagai pelatihan terkait dengan penbuatan handycraft. Kelemahan dari aspek sumber daya manusia yang dimiliki oleh usaha kerajinan mendong adalah para buruh kurang kreatif dalam membuat inovasi produk kerajinan mendong karena mengikuti instruksi dari pemilik usaha kerajinan. Peluang yang dimiliki oleh usaha kerajinan mendong ditinjau dari aspek sumber manusia yaitu mudahnya penyerapan tenaga kerja di sekitaran usaha kerajinan mendong, serta ancaman dari aspek sumber daya manusia yang dimiliki oleh usaha kerajinan mendong di Kelurahan Singkup yaitu para pesaing di bidang industri kerajinan mendong yang ada di luar Kota Tasikmalya memiliki tenaga kerja ahli dalam merancang produk yang mereka hasilkan. (3) Aspek Pemasaran, kekuatan yang dimiliki oleh usaha kerajinan mendong di Kelurahan Singkup ditinjau dari aspek pemasaran yaitu pengusaha kerajinan mendong telah memiliki pangsa pasar (konsumen) dan pemasok yang kontinyu dalam pemesanan produk kerajinan mendong baik yang ada di Jakarta, Yogyakarta dan Malang. Kelemahan yang dimiliki oleh usaha kerajinan mendong di Kelurahan Singkup ditinjau dari aspek pemasaran yaitu promosi hasil industri yang masih belum maksimal, sehingga diduga pengusaha kerajinan mendong di Kelurahan Singkup belum bisa menjual langsung ke pasar yang lebih luas dan belum ada dukungan pemerintah daerah dalam membantu promosi produk. Peluang yang dimiliki oleh usaha mendong di Kelurahan Singkup ditinjau dari aspek pemasaran yaitu permintaan pasar cukup tinggi, terutama pasar luar negeri/ ekspor. Ancaman ditinjau dari aspek pemasaran yang dimiliki oleh usaha kerajinan mendong di Kelurahan Singkup yaitu adanya pesaing di daerah lain yang lebih dekat jaraknya dengan konsumen besar kerajinan mendong. (4) Aspek Keuangan, kekuatan yang dimiliki oleh usaha kerajinan mendong di Kelurahan Singkup ditinjau dari aspek keuangan yaitu modal para 
pengerajin sebagian besar adalah modal pribadi. Kelemahan yang dimiliki oleh usaha kerajinan mendong di Kelurahan

Singkup ditinjau dari aspek keuangan yaitu sistem keuangan usaha yang belum tertata, yakni para pengusaha kerajinan mendong tidak memiliki pembukuan yang sederhana. Peluang yang dimiliki oleh usaha kerajinan mendong di Kelurahan Singkup ditinjau dari aspek keuangan yaitu adanya dukungan dan kepercayaan perbankan dalam pemberian kredit usaha, serta ancaman yang dimiliki oleh usaha kerajinan mendong di Kelurahan Singkup ditinjau dari aspek keuangan yaitu banyaknya pesaing dengan modal yang besar menguasai pangsa pasar.

Berdasarkan hasil analisis kualitatif dan SWOT untuk memperoleh gambaran usaha pengerajin mendong di Kelurahan Singkup pada penelitian ini ditinjau dari aspek produksi, aspek manajemen sumber daya manusia, aspek pemasaran, serta aspek keuangan. Menurut Rangkuti (2001), matrik SWOT adalah alat yang dipakai untuk menyusun faktor-faktor strategis perusahaan. Matrik ini menggambarkan secara jelas bagaimana peluang dan ancaman eksternal yang dihadapi perusahaan dapat diselesaikan kekuatan dan kelemahan yang dimiliki.
Matriks Strengths Weakness Opportunities Threats (SWOT) menurut David (2004), merupakan perangkat pencocokan yang penting yang membantu manajer mengembangkan empat tipe strategi: Strategi SO ( Strengths - Opportunities ), Strategi WO

(Weakness-Opportunities), Strategi ST (Strengths-Threats) dan Strategi WT (Weakness-Threats). Mencocokkan faktorfaktor eksternal dan internal kunci merupakan bagian yang sangat sulit dalam mengembangkan Matriks SWOT dan memerlukan penilaian yang baik dan tidak ada sekumpulan kecocokan yang paling baik. Strategi SO atau strategi kekuatanpeluang menggunakan kekuatan internal perusahaan untuk memanfaatkan peluang eksternal. Strategi WO atau strategi kelemahan-peluang bertujuan untuk memperbaiki kelemahan dengan memanfaatkan peluang eksternal. Strategi ST atau strategi kekuatan-ancaman menggunakan kekuatan perusahaan untuk menghindari atau mengurangi dampak ancaman eksternal. Strategi WT atau strategi kelemahan-ancaman merupakan taktik defensif yang diarahkan untuk mengurangi kelemahan internal dan menghindari ancaman eksternal. 
Melalui identifikasi faktor-faktor internal dan eksternal maka diperoleh kekuatan dan kelemahan serta peluang dan ancaman dengan mengkombinasikan faktor internal dan eksternal maka diperoleh beberapa alternatif strategi yang dapat diterapkan untuk mengembangkan usaha kerajinan mendong di Kelurahan Singkup Kecamatan Purbaratu Kota Tasikmalaya, sebagaimana Tabel 1 .

\section{KESIMPULAN DAN SARAN}

Profil usaha kerajinan mendong di Kelurahan Singkup Kecamatan Purbaratu Kota Tasikmalaya dilihat dari aspek produksi meliputi alat produksi yang berupa ATBM, dengan bahan baku utama mendong lembaran yang telah ditenun dengan berbagai pewarna tekstil untuk dijadikan kerajian tangan berbagai fungsi. Aspek sumber daya manusia adalah tenaga kerja yang dibutuhkan untuk membuat kerajinan mendong dalam satu perusahaan kurang lebih 20 orang dengan sistem pembayaran pengrajin disesuaikan dengan bidang yang dikerjakan dan tenaga kerja pengerajin secara umum merupakan buruh borongan.

Aspek pemasaran kerajinan mendong masih terkendala dalam promosi. Aspek keuangan dari usaha kerajinan mendong masih perlu ditingkatkan dalam pembukuan. Dari analisis SWOT dapat diketahui bahwa produk yang dihasilkan adalah produk kerajinan yang memiliki kualitas yang bagus sehingga dapat dijadikan kekuatan untuk menangkap peluang pasar dengan jumlah pesaing yang cukup tinggi. Dukungan pemerintah sangat dibutuhkan terutama dalam memberikan fasilitasi dan mengikutsertakan dalam berbagai pameran kerajinan. Strategi Bisnis usaha kerajinan mendong diutamakan adalah pengembangan dalam inovasi produk agar lebih kreatif dalam penciptaan bentuk kerajinan tangan yang unik dan berciri khas. 
Tabel 1. Matriks SWOT Strategi Bisnis Usaha Kerajinan Mendong Kelurahan Singkup Kecamatan Purbaratu Kota Tasikmalaya

\begin{tabular}{|c|c|c|}
\hline EKSTERNAL & $\begin{array}{l}\text { Kekuatan-S } \\
\text { 1) Hasil kerajinan yang unik dan } \\
\text { berkualitas } \\
\text { 2) Kemudahan koordinasi dengan } \\
\text { 3) Pengrajin } \\
\text { 4) Memilik usaha kerajinan berpengalaman } \\
\text { 4) }\end{array}$ & $\begin{array}{l}\text { Kelemahan-W } \\
\text { 1) Perencanaan Produksi } \\
\text { belum maksimal } \\
\text { 2) Kurang inovasi dan } \\
\text { kreatifitas } \\
\text { 3) Promosi belum maksimal } \\
\text { 4) Belum ada pembukuan } \\
\text { yang } \\
\text { tersusun lengkap }\end{array}$ \\
\hline $\begin{array}{ll}\text { Peluang-O } \\
\text { 1) } \\
\text { Memiliki kerjasama } \\
\text { dengan pemasok } \\
\text { pemasok bahan baku } \\
\text { 2) } \begin{array}{l}\text { Memperluas lapangan } \\
\text { kerja }\end{array} \\
\text { 3) Permintaan ekspor cukup } \\
\text { tinggi } \\
\text { 4) Memiliki kepercayaan dari } \\
\text { perbankan } \\
\text { Memiliki pangsa pasar } \\
\text { yang } \\
\text { kontinyu }\end{array}$ & 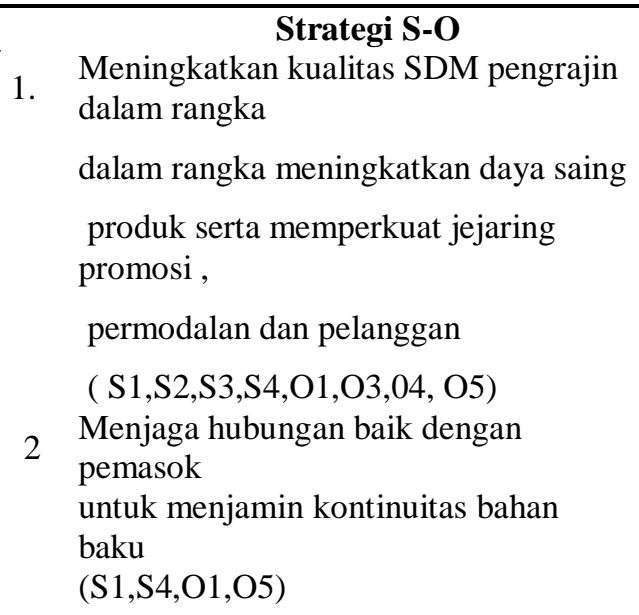 & 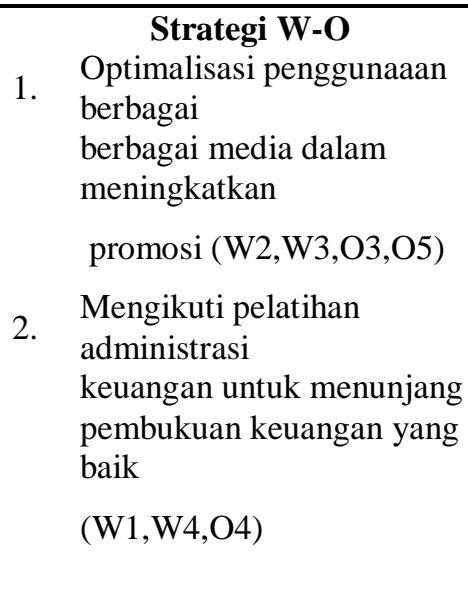 \\
\hline $\begin{array}{l}\text { Ancaman-T } \\
\text { 1) Fluktuasi harga bahan baku } \\
\text { yang berasal dari luar kota } \\
\text { 2) Produk Pesaing lebih } \\
\text { inovatif } \\
\text { 3) Pesaing memiliki lokasi } \\
\text { yang } \\
\text { lebih dekat dengan } \\
\text { konsumen } \\
\text { Pesaing memiliki modal } \\
\text { yang } \\
\text { lebih besar } \\
\text { Tidak ada regenerasi } \\
\text { pengrajin }\end{array}$ & $\begin{array}{l}\text { Strategi S-T } \\
\text { 1. } \begin{array}{l}\text { Meningkatkan efisiensi produk dan } \\
\text { margin } \\
\text { dengan menggunakan saluran distribusi }\end{array} \\
\text { yang pendek (S1,S2,S4, T1,T2,T3,T4) } \\
\text { 2. } \begin{array}{l}\text { Menjaga kepercayaan pelanggan } \\
\text { dengan }\end{array} \\
\text { kualitas produk melalui manajemen } \\
\text { produksi yang baik (S1,S3,T2,T3,T4) }\end{array}$ & \begin{tabular}{l}
\multicolumn{1}{c}{ Strategi W-T } \\
Meningkatkan inovasi dan \\
promosi \\
produk dengan melihat \\
perkembangan \\
pasar (W2,W3,T2,T3,T4) \\
Melibatkan generasi \\
penerus untuk \\
terjun mengembangkan \\
inovasi dan \\
membuat pembukuan \\
keuangan \\
(W1,W2,W3,W4, \\
T2,T3,T4,T5)
\end{tabular} \\
\hline
\end{tabular}




\section{DAFTAR PUSTAKA}

David, F R. 2004. Manajemen Strategis Konsep-Konsep. Terjemahan. PT. Indeks Kelompok Gramedia. Jakarta.

Griffin, Ricky W. 2004. Manajemen. Edisi ke-7. Jakarta: Erlangga.

Hanipah, E. 2017. Analisa Sentra Industri Kerajinan Mendong di Kecamatan Purbaratu Kota Tasikmalaya (Pendekatan Quintuple Helix). Jurnal Universitas Muhamadyah Yogyakarta.

Mahmud dan Anomsari, Analisis Pengaruh Orientasi Kewirausahaan, Kemampuan Manajemen, dan Strategi Bisnis Dalam Peningkatan Kinerja Perusahaan (Studi Pada Usaha Kecil Menengah di Kawasan Usaha Barito Semarang), Seminar Nasional Teknologi Informasi \& Komunikasi Terapan 2011 (Semantik 2011), 2011, hal. 3.

Rangkuti, F. 2001. Analisis SWOT Teknik Membedah Kasus Bisnis. Gramedia Pustaka Utama. Jakarta.
Suprayatni, M, Suharso, N, Dunia, K. 2014. Analisis SWOT terhadap profil usaha kerajinan kain tenun Desa Tanglad Kecamatan Nusa Penida Kabupaten Klungkung. Jurnal Universitas Pendidikan Ganesha Singaraja. Vol.4 No.1. Tahun 2014.

Suryana. 2008. Kewirausahaan. Pedoman Praktis:Kiat Menuju Sukses . jakarta: Salemba Empat.

Utami, K S. 2016. Analisis SWOT (Strengths, Weaknesses, Opportunities, Threats) Kerajinan Kreatif Anyaman Mendong di Kabupaten Sleman. Jurnal Solusi Kajian Informasi dan Bisnis. Volume 11 Nomor 2 Tahun 2016.

Utomo, D T. 2010. Strategi Pemasaran Anyaman Tikar Berbahan Baku Mendong (Cyperus Sp) di Kabupaten Wonogiri. Skripsi Universitas Sebelas Maret. Surakarta 